Ciência Rural, Santa Maria, 21(2): 275-281, 1991 . Aprov. p/ publicação em 04/09/91.

\title{
INTERSEXUALIDADE EM HUSKY SIBERIANO: RELATO DE UM CASO.
}

\section{INTERSEXUALITY IN A SIBERIAN HUSKY: A CASE REPORT.}

Elgion Lúcio da Silva Loreto*

Luciana Silveira Flores SchoRenato Zamora Flores***

\section{RESUMO}

Hermafroditismo e pseudohermafroditismo são fenômenos relativamente raros em cães. Descreve-se aqui um possível caso de pseudo-hermafroditismo masculino. o cão em estudo apresentava genitália ambígua, sendo tratado até os quatro meses de idade como fêmea. O estudo da cromatina do $x$ em mucosa bucal foi negativo e o cariótipo de sangue periférico apresentou 78, XY cromossomos. A análise radiológica evidenciou uma uretra de trajeto feminino e a presença de uma estrutura piriforme compatível com vagina cranial, o que justificava a presença de incontinência urinária. Com relação a aspectos etológicos, o animal manifestava comportamento masculino.
Palavras-chave: intersexualidade, pseudo-hermafroditismo, genitália ambígua, incontinência urinária.

\section{SUMMARY}

Hermaphroditism and pseudohermaphroditism are relatively rare phenomenon in dogs. A possible case of male pseudohermaphroditism is described here. The studied dog showed ambiguos genitalia pseudohermaphroditism and was thought to be a female until four months of age. The $x$-chromatin in cells of buccal smears was negative, and the karyotype of peripheric blood had 78, XY, chromosomes. Radiological analysis

\footnotetext{
* Prof. Assistente do Departamento de Biologia, Universidade Federal de Santa Maria. 97.119 - Santa Maria, RS.

** Médico Veterinário, aluna do Curso de Pós-Graduação em Medicina Veterinária, Universidade Federal de Santa Maria. 97.119 - Santa Maria, RS.

$\star \star \star$ Prof. Assistente do Departamento de Genética - IB - Universidade Federal do Rio Grande do Sul. 90.000 - PORTO ALEGRE - RS.
} 
revealed an urethra with feminine course and the presence of one piriform structure compatible with cranial vagine, that could explain the urynary incontinence. Concerning the ethological aspects, this dog showed male behavior.

Key Words: intersexuality, pseudohermafroditism, ambiguos genitalia, urynary incontinence.

\section{INTRODUÇÃO}

A intersexualidade é considerada um fenômeno raro em cães (HARE, 1986) podendo ser classificado em 3 tipos: (1) hermafroditismo verdadeiro, quando os tecidos gonadais são de ambos os sexos; (2) pseudo-hermafroditismo masculino, quando possui tecido gonadal testicular e órgãos genitais com características femininas e (3) pseudo-hermafroditismo feminino, quando possui tecido gonadal ovariano e órgãos genitais com alguma característica masculina (MURTI et al, 1966). Segundo MIALOT (1988), o pseudohermafroditismo masculino é $\mathrm{ca}^{-}$ racterizado pela presença de testículos e também de diversas anomalias dos órgãos sexuais: criptorquidismo, hipospadias, ausência de prepúcio ou existência de orgãos sexuais afeminados e os cariotipos, no homem, geralmente são XX ou XY, XY/XO.

0 desenvolvimento normal ocorre em três níveis sexual principais, sendo a progressão para o próximo nível dependente da terminalização correta do anterior. Estes níveis são: (1) estabelecimento do sexo cromossômico; (2) desenvolvimento do sexo gonadal, e (3) desenvolvimento do sexo fenotípico. Em cães, como na maioria dos mamíferos, o sexo dos indivíduos é determinado na fertilização. Se o sexo cromossômico for XX, ovários irão desenvolver-se, já o desenvolvimento de testículos depende da presença do cromossomo $Y$ (MEYERS-WALLEN \& PATTERSON, 1986). PAGE et al (1987) clonaram um gene humano, presente no braço curto do cromossomo $Y$, que é altamente conservado na escala evolutiva e denominado "fator determinante de testículos", o qual é necessário e suficiente para induzir a diferenciação testicular. Esse gene também é encontrado em cães. 0 desenvolvimento de genitália interna e externa depende da presença ou ausência de testículos. A gonadectomia de embriões $\mathrm{XX}$ ou $X Y$ antes da diferenciação gonadal resulta no desenvolvimento de fenótipo feminino (JOST, 1972). O fenótipo masculino é resultado do desenvolvimento de testiculos, que muda o plano feminino de desenvolvimento pela secreção de testosterona e da substância inibidora dos ductos mullerianos.

Descreve-se aqui um possivel caso de pseudo-hermafroditismo masculino em um cão da raça Husky Siberiano, nascido em uma ninhada de oito (dois machos, quatro fêmeas e um natimorto com malformações de linha média) que foi criado até quatro meses como fêmea, quando verificou-se a pre- 
sença de genitália ambígua por exteriorização de um micropênis.

\section{RELATO DE CASO}

\section{Estudo clínico e etológico}

Constou de exames clínicos externos e da avaliação macroscópica dos orgãos genitais. Para estudar o comportamento, esperou-se até o animal completar a pressuposta maturidade sexual (ao redor de 10 meses).

\section{Estudos citogenéticos}

Estudamos a cromatina do $\mathrm{X}$ através de esfregaço de mucosa bucal e o cariótipo através de cultura de. linfócitos do sangue periférico.

\section{Estudos radiológicos}

Foram realizadas radiografias simples e contrastadas nas posições ventro-dorsal e lateral. Das contrastadas realizou-se uretrocistografia retrógrada e urografia excretora. Para urografia retrógrada foi introduzida no orifício uretral do micropênis uma sonda uretral ne 4 que não progrediu até a bexiga, trancando em um determinado ponto. Foram injetados através da sonda $10 \mathrm{ml}$ de uma solução contrastada de diatrizoato de sódio e diatrizoato de meglumine. A urografia excretora foi realizada por injeção intravenosa de $20 \mathrm{ml}(2 \mathrm{ml} / \mathrm{kg})$ da mesma solução contrastada.

\section{RESULTADOS}

\section{Sexo cromossômico}

o resultado da análise da cromatina do $X$ em mucosa bucal foi negativo em duas coletas, usando-se como controle positivo a mãe do probando. 0 cariótipo elaborado a partir de células de sangue periférico apresentou $78, X Y$ cromossomos, em 65 metáfases analisadas, sendo 0 característico de machos normais. O cromossomo $X$ pode ser facilmente identificado por ser maior e metacêntrico (Figura 1).

\section{Avaliação clínica}

A análise da morfologia externa revelou a presença de uma genitália ambígua, localizada em posição intermediária entre vulva e prepúcio normais. Através de pressão nesta estrutura, um micropênis de aproximadamente $3,5 \mathrm{~cm}$ com osso peniano, era exteriorizado. O orifício uretral encontrava-se em posição anormal revelando uma hipospádia. (Figura 2 ). Não havia vestígio de saco escrotal e a presença de testículos não pode ser evidenciada por palpação abdominal. Foi observada incontinência urinária, manifestada pela presença de pequena quantidade de urina no local onde o cão deitava.

Foi tentada a dosagem de testosterona em duas oportunidades, através de Radio imuno ensaio para o hormônio humano. O resultado do animal e de seu irmão, macho normal, foi negativo em ambas tentativas. 

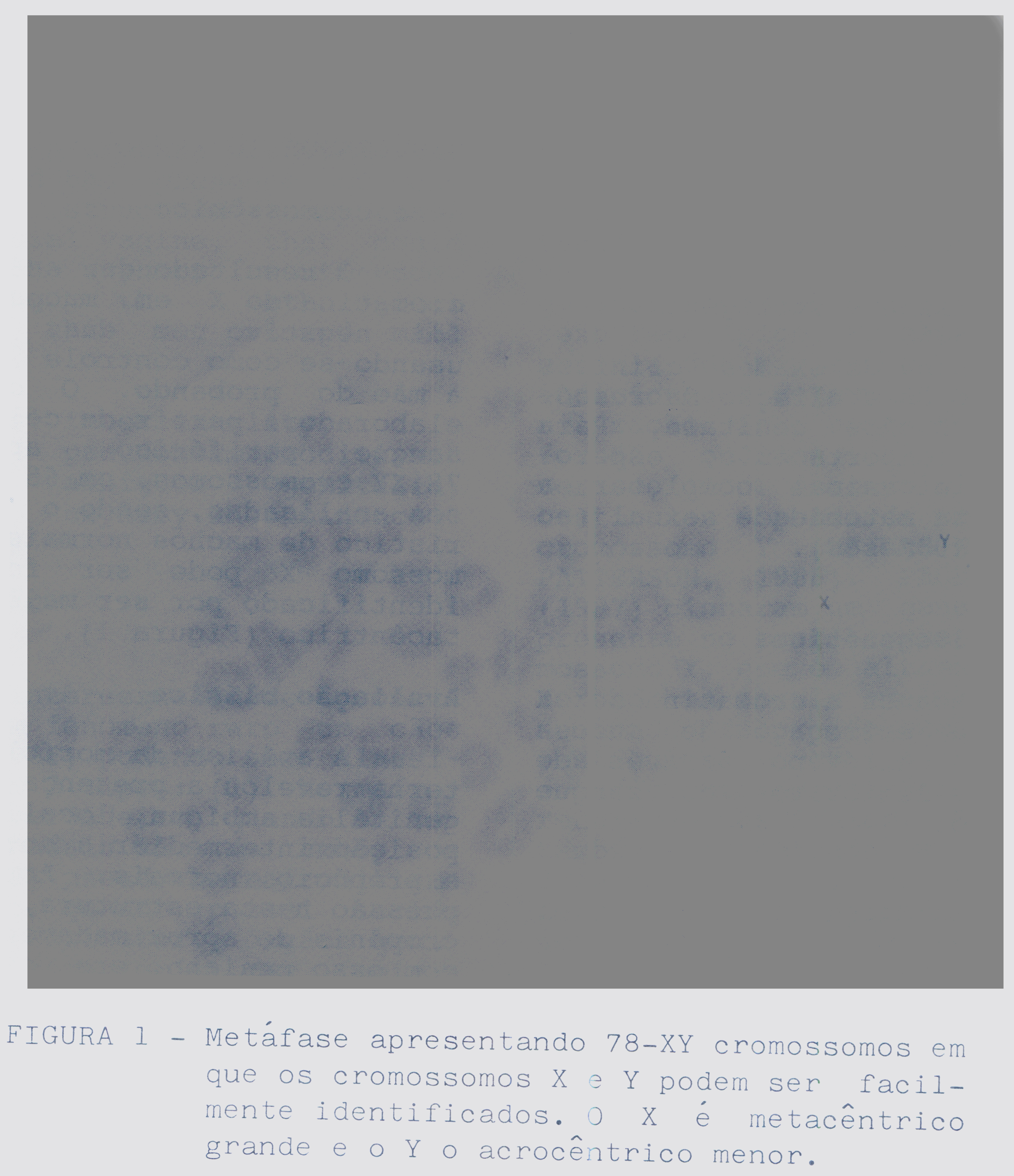

\section{Estudos radiológicos}

$\mathrm{Na}$ uretrocistografia retrógrada em posição lateral, ceu na região pélvica uma apareestrutura piriforme, compatível com vagina cranial, na qual desembocava a uretra. Antes de chegar nesta estrutura a uretra continuava-se no sentido cranio-abdominal até a bexiga. A uretra foi considerada no presente estudo como de trajeto feminino (Figura 3 ) .

$$
\text { A posição ventro-dorsal }
$$
confirmou a presença desta estru- 
tura, assim como as posições lateral e ventro-dorsal da urografia excretora. Evidenciou-se também a presença de ureteres perfeitamente normais, assim como a bexiga.

TABELA 2 - Genitália ambígua, em que se pode notar a presença do micropênis com hipospádia.


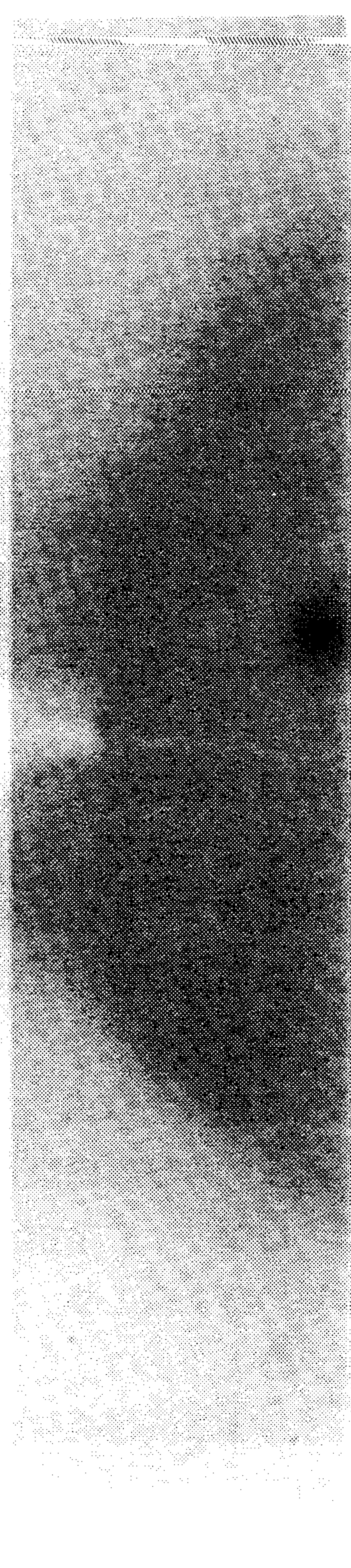

FIGURA 2 - Uretrocistografia ventro-dorsal em que se observa a estrutura piriforme, compative 1 com vagina cranial. 


\section{DISCUSSÃO}

HARE (1976) relatou que pseudo-hermafroditismo masculino acontece em $50 \%$ dos casos de intersexualidade de cães, baseando-se no tecido gonadal e na genitália ambígua. Descreve também que dos casos estudados onde foram realizadas avaliações do sexo genético 7 eram $X Y$ e cinco $X X$, concordando com $O$ caso descrito onde foi constatado $X Y$.

A localização anormal da genitália ambígua, estando intermediária às posições normais da vulva e prepúcio foi também relatado por DAIN (1974), HINSCH $(1979)$ e EDWARD ALLEN et al (1981).

DAIN (1974) descreve um caso de pseudo-hermafrodita macho que foi considerado fêmea ao nascimento, mas que mais tarde provou ter genitália externa de sexo indeterminado. Foi constatada a presença de um pequeno pênis de aproximadamente seis centrímetros que continha osso peniano e uretra hipospádica. Outro caso descrito por MURTI et al (1966) como fenótipo de fêmea, revelou a presença de uma estrutura como pênis de $3,7 \mathrm{~cm}$ e com osso peniano. Estes casos assemelham-se ao presente onde $O$ micropênis possuia osso peniano, uretra hipospádica e media ao redor de $3,5 \mathrm{~cm}$.

Os cães apresentam um dimorfismo comportamental acentuado, servindo o estudo do comportamento animal como subsídio para análise de estruturas biológicas. EDWARD ALLEN et al (1981) descrevem um caso de hermafroditismo verdadeiro onde o cão manifestava comportamento masculino, montando outras fêmeas. Relata também um caso de pseudo-hermafrodita fêmea que era atrativa para cães machos. O comportamento masculino está relacionado com a presença do hormônio masculino testosterona que é produzido pelas células de Leydig nos testículos. Assim o comportamento de tentar coito em fêmeas no cio e o de alçar a perna para urinar, no presente caso, sugere a presença de tecido testicular, descartando a hipótese de pseudo-hermafroditismo feminino. A análise histológica das gonadas não pode ser realizada, pois o animal foi perdido antes que pudesse ser realizada tal avaliação.

Para JACKSON et al (1978) a incontinência urinária não neurogênica parece ser um achado comum em pseudo-hermafroditismo canino, associado com anormalidades na vagina ou uretra (ou ambas). 0 caso descrito por estes autores revela uma comunicação anômala entre a uretra e a vagina com imagem radiológica semelhante ao presente caso. CARRILO e BURK (1977) apresentaram um caso de pseudo-hermafroditismo masculino com incontinência urinária onde radiografias abdominais com contraste negativo (ar) revelaram a presença de uma estrutura localizada ventral ao colon e dorsal a bexiga. No presente caso, como o contraste preencheu a estrutura piriforme durante a realização da urografia excretora, isto indicou que o mesmo ocorria com a urina durante a micção, deixando um resíduo de urina pós-micção que causava a incontinência urinăria. 


\section{CONCLUSÕES}

Os dados indicam que este cão apresentava anormalidades no sexo fenotípico, sendo provavelmente um pseudo-hermafrodita masculino, ainda que não tenha sido possível a análise histológica da gonada. Embora o cão em estudo fosse cromossômicamente masculino e apresentasse a genitália com características femininas, esta possuia certo grau de masculinização, que reflete necessariamente a presença de testosterona. Observações comportamentais reforçam esta hipótese, uma vez que - cão apresentava alguns comportamentos tipicamente masculinos.

\section{AGRADECIMENTOS}

Os autores agradecem ao Prof. LUIS CARLOS PELEGRINI pela execução do serviço radiológico.

\section{REFERÊNCIAS BIBLIOGRÁFICAS}

CARRILO, J.M., BURK, R.L. Male pseudohermaphroditism

associated with urynary incontinence in a Afghan. J Amer Anim Hosp Assoc, v. 13, n. 1 , p. 80-82, 1982 .

DAIN, A.R. Intersexuality in a Cocker Spaniel dog. J Reprod Fert, v. 39, p. 365-371, 1974. EDWARD ALLEN, W. , DAKER, M.G., HANCOCK, J.L. Three intersexual dogs. Vet Rec, v. 10.9, p. 468-471, 1981 .

HARE, W.C.D. Intersexuality in the dog. Can vet $\mathbf{J}, \mathrm{v}, 17, \mathrm{n}$. $1, \mathrm{p} .7-15,1976$.

HINSCH, E.W. Intersexes in the dog. Terat, v. 20, p. 463-468, 1979 .

JACKSON, D.A., OSBORNE, C.A., BRASMER, T.H. et al. Non-neurogenic urynary incontinence in a canine female pseudohermaphrodite. J Amer Vet Med Assoc, v. 172, n. 8, p. 926-930, 1978 .

JOST, A. A new look at the mechanisms controlling sex differentiation in mammals. Johns Hop Med $J, v .130$, p. 39-53, 1972 .

MEYERS-WALLEN, V.N., PATTERSON, D.F. Sexual differentiation and inherited disorder of sexual development in the dog. $J$ Reprod Fert Suppl, v. 39, p. 57-64, 1989 .

MIALOT, J.P. Patologia da reprodução dos carnívoros domésticos. Porto Alegre: A Hora Veterinária, 1988. cap. 5: Patologia do aparelho genital feminino: p. 44-60.

MURTI, C.S., GILBERT, D.L., BORGMANN, A.R. Canine intersex states. J Amer Vet Med Assoc, v. 149, n. 9, p. 1183-1185, 1966 .

PAGE, D.C. The sex determining region of the human $Y$ chromosome encodes a finger protein. Cell,. v. 51, p. 1091-1984, 1987 . 